NP5 (continued)

Nashville, TN 37208; M. Etling, MD, PhD, MSPH, Meharry Medical College; R. Levine, MD; J. Emerson, $\mathrm{PhD}$, Tennessee State University; B. Husaini, PhD

Objective: Increase knowledge and skills about nutrition and childhood obesity prevention among Tennessee State University and Meharry students/trainees and practicing healthcare providers.

Description: A total of 870.25 trainee-hours of education were provided for 246 students/trainees and practicing physicians this year. Success of CHEW collaboration presented at the 142nd Annual American Public Health Association conference.

Evaluation: Improved knowledge of nutrition concepts related to chronic diseases achieved among third year medical students for topics related to dietary recommendations for diabetics $(\mathrm{p}<0.0001)$, screening for hyperlipidemia $(\mathrm{p}=0.007)$, indications for lifestyle modification $(\mathrm{p}=0.008)$, and dietary recommendations for the implementation of lifestyle modifications $(\mathrm{p}<0.0001)$.

Conclusions and Implications: Contributes to training next generation of professionals.

Funding: USDA Grant \#2011-68001-30113.

\section{NP6 Nashville Children Eating Well (CHEW) for Health: Extension Component}

Chiquita Briley,PhD, cbriley1@tnstate.edu, Tennessee State University, College of Agriculture, 3500 John A. Merritt Boulevard, Nashville, TN 37209-1561; B. Canada, PhD; J. Jones, MS; J. Canedo, MA, Progreso Community Center; D. Schlundt, $P h D$, Vanderbilt University

Objective: Provide technical assistance to WIC-authorized vendors to expand the availability of healthy foods and educate low-income families to improve dietary practices.

Description: Provided technical assistance and in-store food tastings twice a year to the 18 participating WIC vendors. Trained 8 African American and Hispanic Community Health Promoters (CHPs) to educate peer low-income mothers with young children.

Evaluation: There were 2,393 community contacts including CHPs, grocery store food tastings and community outreach this year which increases the total number of community contacts for the project to 3,653 with a total of 208.2 contact hours.

Conclusions and Implications: Multi-level approach address food environment and individual education.

Funding: USDA Grant \#2011-68001-30113.

NP7 Nashville Children Eating Well (CHEW) for Health: Smartphone Intervention for WICParticipating Families With Preschool Children

Pamela Hull,PhD, pam.hull@vanderbilt.edu, Vanderbilt University School of Medicine, 2525 West End Avenue, Suite 800, Nashville, TN 37203; J. Emerson, PhD, Tennessee State University; M. Quirk, PhD;

D. Schmidt, PhD, Vanderbilt University; S. Mulvaney, PhD; B. Beech, DrPH, University of Mississippi Medical Center; B. Husaini, PhD, Tennessee State University
Objective: Evaluate a culturally-appropriate smartphonebased nutrition intervention for African American and Hispanic WIC participants with preschool children.

Description: The smartphone application (English and Spanish) has two components: a WIC shopping tool to assist mothers with maximizing WIC vouchers, and nutrition education focused on healthy snacks and beverages.

Evaluation: We are testing the application using a randomized two-group design, to assess feasibility, usability, and effects on dietary behaviors, availability of healthy food in the home, parent snack feeding practices, and WIC shopping experiences. Preliminary data will be presented.

Conclusions and Implications: The application can be adapted and disseminated to WIC programs across the U.S. in the future.

Funding: USDA Grant \#2011-68001-30113.

\section{NP8 Nashville Children Eating Well (CHEW) for Health: Website Effectiveness}

Janice Emerson,PhD, jemerson@tnstate.edu, Tennessee State University, 3500 John A. Merritt Boulevard, Box 9580, Nashville, TN 37209-1561; P. Hull, PhD, Vanderbilt University School of Medicine; R. Levine, MD, Meharry Medical College; C. Briley, PhD, Tennessee State University; B. Husaini, PhD

Objective: Long-term, CHEW aims to reduce childhood obesity.

Description: CHEW assists and educates USDA's Women, Infants \& Children (WIC) program families with 2-4 year olds; WIC grocers serving this population; nutrition and medical students; health providers and other community members.

Evaluation: NashvilleCHEW.org website, online since June 2012, averaged over 6,000 views a month in 2014 with a peak of over 18,000 views in November. Website includes healthy snack recipes in English and Spanish; nutrition lectures, calendar of healthy food tastings, CHEW conferences presentations.

Conclusions and Implications: Community outreach through a website can be effective in focusing attention on culturally tailored nutrition education and obesity prevention efforts.

Funding: USDA Grant \#2011-68001-30113.

\section{NP9 Smarter Lunchrooms - Does Changing Environments Really Give More Nutritional Bang for the Buck?}

BrianWansink,PhD, wansink@cornell.edu, Cornell University, Charles H. Dyson School of Applied Economics and Management, 475 Warren Hall, Ithaca, NY 14853; D. Just, PhD; J. Dollahite, PhD; T. Hill, MPH; A. Gaines, PhD; A. Brumberg,; K. Greene, MPH

Objective: To test a combination of Smarter Lunchroom conditions using a randomized controlled design in order to determine their cumulative effect. 
NP9 (continued)

Description: The treatment received by intervention schools was promotion of low-fat white milk, fruits, and vegetables. For the fall, 6 intervention (3 urban, 3 rural) and 6 control schools participated. In the spring, the control schools will become intervention schools, while fall interventions become maintenance schools.

Evaluation: Process and outcome measures were collected.

Conclusions and Implications: Most treatments were feasible to implement. Initial analysis indicates reduction in waste in treatment schools for entrees, fruit, and milk. The spring intervention is in progress.

Funding: USDA Grant \#2012-68001-19604.

\section{NP10 Factors That Enhance Application of an Ecological Approach to Preventing Childhood Obesity}

Christina Stark, MS, RD, CDN, cms11@cornell.edu, Cornell University, Division of Nutritional Sciences, Savage Hall, Ithaca, NY 14853; J. Dollahite, PhD; C. Devine, PhD, $R D$

Objective: The objective was to determine what factors influence application of an ecological approach by extension professionals.

Description: An online training course was delivered to 383 professionals, either as teams of extension/community partners or individuals.

Evaluation: Outcomes were assessed at course end and six-month follow-up using matched surveys $(n=240)$. Behavioral intentions, credential, work experience, networking utility, job scope, job support, and funding were associated with application of an ecological approach at follow-up $(\mathrm{P}<.05)$.

Conclusions and Implications: Certain personal and organizational factors can enhance professionals' ability to apply an ecological approach at the community level.

Funding: USDA Grant \#2010-85215-20665, USDA Smith-Lever and Hatch funds supported the delivery and evaluation of the online course to New York State professionals including Cornell Cooperative Extension educators.

\section{NP11 CH0ICES: A Family-Based Childhood Obesity Intervention for Low-Income Minority Children}

Cynthia Williams,PhD, williamsc@wssu.edu, WinstonSalem State University, 601 Martin Luther King Jr. Drive, Anderson Center Suite 146, Winston-Salem, NC 27110

Objective: The objective of this presentation is to discuss the effectiveness of a 6-week summer childhood obesity intervention for low-income minority children ages 10-12.

Description: Topics will include strategies and best practices for effective summer programming for youth. The target audience includes practitioners, educators, and researchers interested in childhood obesity interventions involving families and communities.

Evaluation: Project results will include a mixture of quantitative (BMI, Body Image, etc.) and qualitative (focus groups) data analysis.

Conclusions and Implications: The presentation will also include suggestions for best practices for childhood obesity interventions focusing on high-risk populations of low-income families.

Funding: USDA Grant \#2013-04365.

\section{NP12 Why Generate Rural Options for Weight Healthy Kids and Communities?}

Deborah John,PhD, deborah.john@oregonstate.edu, Oregon State University, 345 Hallie E. Ford Center, College of Public Health and Human Sciences, Corvallis, OR 97331; K. Gunter, PhD; M. Manore, PhD;

G. Langellotto, PhD; P. Hystad

Objective: A multi-level contextual model for rural obesity prevention was created and tested in Oregon to improve weight-healthy behaviors and BMI among elementary school-aged children.

Description: Measures were applied at various levels to track person-level and environmental changes.

Evaluation: Obesity is inversely associated with physical activity among 1st-6th graders, and food insecure families are less likely to provision PA opportunities for children. Rural communities, schools and families are inadequately resourced to support children's weight-healthy behaviors.

Conclusions and Implications: Improvements in the proximal food and activity context at multiple environmental levels are required to balance children's energy equation and reverse the rural obesity trend.

Funding: USDA Grant \#2011-68001-30020.

\section{NP13 Salud Para Usted Y Su Familia [Health For You and Your Family]: Childhood Obesity Prevention In Arizona, New Mexico, and Texas Border Areas \\ Joseph Sharkey,PhD, MPH, RD, jrsharkey@sph.tamhsc.edu, Texas A\&M School of Public Health, MS 1266, College Station, TX 77843-1266; J. McDonald, PhD, MS, New Mexico State University; S. Kunz, MPH, Mariposa Community Health Center; M. R. Umstattd Meyer, PhD, MCHES, Baylor University}

Objective: The long-term goal of Salud Para Usted y Su Familia [Health for You and Your Family (SPUSF)] is to reduce the incidence of overweight and obesity among Mexican-heritage children from limited- resource colonias/neighborhoods along the Arizona, New Mexico, and Texas borders with Mexico. 